\title{
Isosorbide mononitrate followed by misoprostol compared with misoprostol alone for induction of labour at term: a randomized controlled trial
}

\author{
Shikha Agarwal, Kusum Dogra \\ Corresponding author: Dr. Kusum Dogra, Assistant Professor, Department of Obs \& Gynae, UCMS \\ \& GTB hospital, Delhi, India; Email : drkusumdogra@gmail.com
}

Distributed under Attribution-Non Commercial - Share Alike 4.0 International (CC BY-NC-SA 4.0)

\begin{abstract}
Background: The rate of induction of labour is on rise globally due to various indications. The use of well established methods for induction of labour like prostaglandins is associated with various maternal and fetal adverse effects. Objective: Present study was designed to investigate the efficacy and safety of Nitric Oxide (NO) donor, Isosorbide mononitrate (ISMN) for cervical ripening and labour induction. To see the effect of sequential use of ISMN followed by misoprostol compared to misoprostol alone on induction of labour at term. Methods: This prospective randomized controlled trial was conducted from May 2012 to April 2013. Total 100 women, who fulfilled the inclusion criteria were admitted for labor induction during the study period. Study group received $60 \mathrm{mg}$ sustained release tablet of Isosorbide mononitrate (ISMN) and control group received placebo, per vaginally, for cervical ripening. Bishop score was reassessed after 16 hours and participants in each group received $25 \mathrm{mcg}$ of misoprostol tablet per vaginally at $4 \mathrm{hrs}$ interval for maximum of 4 doses till 3 contraction in $10 \mathrm{~min}$ or if cervix was dilated $3 \mathrm{~cm}$ or more. Progress of labor was monitored using partograph. Results: There was significant difference between ISMN group and control group with respect to mean Bishop score $(5.5 \pm 0.54$ verses $4.16 \pm 0.76$, p value $<0.001)$. Vaginal delivery were more in ISMN group ( $66 \%$ vs $32 \%$ ), so caesarean section were less in ISMN group ( $34 \%$ vs $68 \%$, $\mathrm{p}=0.46$ ). Lesser doses of misoprostol was required in ISMN group and reduced requirement of oxytocin to achieve vaginal delivery in ISMN group as compared to control group $(9.1 \%$ vs $81.25 \%, \mathrm{p}=0.001)$. Induction to vaginal delivery interval less than $12 \mathrm{hrs}$ was seen on 54\% cases in study group whereas none patient delivered in this interval in control group which was statistically significant $(\mathrm{p}=0.0002)$. Major side effect of ISMN was headache which responded to analgesia. Conclusion: ISMN is an ideal agent for effective cervical ripening, which induces ripening of cervix without causing uterine contraction. It significantly improves mean Bishop score, reduces the number of misoprostol doses required to achieve vaginal delivery and less induction failure.
\end{abstract}

Keywords: Isosorbide mononitrate (ISMN), NO donors (Nitric oxide donors).

Induction of labor is on rise and is a common phenomenon in modern obstetrics. Although prospective studies for evaluation of the benefits of elective induction are limited, primiparous women undergoing induction of labour with unfavourable cervices should be counseled about two fold increased risk of caesarean delivery ${ }^{1-3}$. Various pharmacological as well as non-pharmacological methods are available for cervical ripening. When Bishop score is favorable, oxytocin also may be used ${ }^{4}$ as it has been widely used since $1950 \mathrm{~s}$ for cervical ripening and induction of labour. 5

Prostaglandins, particularly dinoprostone (PGE2) has been used as pre-induction cervical ripening however, it is expensive, unstable at room temperature and requires refrigeration for storage. ${ }^{6}$ The only drawback appears to be an increase rate of uterine stimulation and accompanying

Received: $6^{\text {th }}$ December 2020, Peer review completed: $5^{\text {th }}$ March 2021, Accepted: $7^{\text {th }}$ March 2021.

Agarwal S, Dogra K. Isosorbide mononitrate followed by misoprostol compared with misoprostol alone for induction of labour at term: a randomized controlled trial. The New Indian Journal of OBGYN. 2022; 8(2): 289 - 94. 
fetal heart rate (FHR) changes.

Misoprostol is an interesting alternative, with good efficacy, low cost and temperature stability. ${ }^{7} \mathrm{~A}$ meta-analysis based on Cochrane database review concluded that vaginal administration of misoprostol is effective for induction of labour. ${ }^{8}$ Despite the widespread use and low dose recommendation for labour induction, prostaglandins are associated with various adverse effects which have always led to a search for an ideal ripening agent to induce cervical ripening without stimulating uterine contractions and other harmful effects on fetus. In this context, nitric oxide (NO) donors may prove to be an important milestone as an agent for pre induction cervical ripening. NO donors can induce cervical ripening without stimulating myometrial contractility. Isosorbide mononitrate (ISMN), a NO donor, induces cyclo-oxygenase-2 which leads to the production of endogenous prostaglandins in human cervix and causes ultra structural rearrangement in the cervix similar to spontaneous onset of labour. ${ }^{9}$

The recognition of nitric oxide donors as a better cervical ripening agent without significant adverse effect has opened new avenues of investigation for use of NO donors for induction of labor at term with an unripe cervix. In view of this, present study was undertaken to see the usefulness of ISMN for pre-induction cervical ripening followed by misoprostol $25 \mathrm{mcg}$ every $4 \mathrm{hrs}$ for maximum of 4 doses. Primary objective was to investigate the efficacy and safety of NO donor, Isosorbide mononitrate (ISMN) for cervical ripening and labour induction. Secondary objective was to see whether sequential use of misoprostol with prior ripening of cervix reduces the induction to delivery interval, decreases the number of misoprostol doses and further reduces the side effects associated with other more potent uterotonics.

\section{Materials and method}

This prospective randomized controlled trial was conducted in the department of Obstetric and Gynecology at ESIPGIMSR \& ESIC Hospital \& ODC (EZ), Joka, Kolkata between May 2012 to April 2013. Before initiation, study was approved by ethical committee of the university. Women were explained about induction of labour and study protocol and informed written consent was taken. Total 100 women, who fulfilled the inclusion criteria, were admitted for labor induction.

Inclusion criteria includes singleton live pregnancy at term in cephalic presentation, absence of active labor, presence of obstetric or medical indication for labor induction viz postdated, bishop score less than 6 .
Whereas exclusion criteria includes multipara (3 or more), known hypersensitivity to the use of prostaglandins, previous caesarean section, or any other types of uterine surgery like myomectomy, fetal macrosomia or growth restriction, malpresentation, FHR abnormalities, maternal medical disorders, cephalopelvic disproportion, Bishop score more than or equal to 6 , multiple pregnancy.

Detailed history and examination of patients were taken. At admission cardiotocography was done to ensure normal fetal heart activity. Pelvic examination was done to assess Bishop score and to rule out cephalo-pelvic disproportion. Total 100 women gave consent to participate in the study and were randomized under two groups.

Randomization: Simple randomization method was used. Patients were allocated to two groups (Study group and Control group) by computer generated random number. The participants were enrolled and assigned to ISMN group and placebo group in accordance with list of code. This was a single blinded trial as participants were not aware about the allocation of group and intervention given. Study group received $60 \mathrm{mg}$ sustained release tablet of isosorbide mononitrate (ISMN) and control group received placebo, per vaginally, for cervical ripening.

Bishop score was reassessed after 16 hours and participants in each group received $25 \mathrm{mcg}$ of misoprostol tablet per vaginally at $4 \mathrm{hrs}$ interval for maximum of 4 doses till 3 contraction in $10 \mathrm{~min}$ or if cervix was dilated $3 \mathrm{~cm}$ or more. Progress of labor was monitored using partograph. Various findings are noted viz. improvement of mean Bishop score, mode of delivery, indication for caesarean section, need for misoprostol and oxytocin, induction to delivery interval, maternal and fetal condition during labor.

Statistical analysis: Nominal data were expressed as percentage and comparison between two groups were done by Chi square test with Yates correction and Fisher's extract test. The "p" value $<0.05$ was considered statistically significant.

\section{Results}

Baseline demographic characteristics of both groups were comparable. Mean age for study group was $22.2 \pm 3.8 \mathrm{yrs}$ and for control group was $21.9 \pm 2.8$ yrs which was comparable in both groups. A total number of 50 cases were enrolled in each group. Out of 50 cases $39(78 \%)$ in study group and $84 \%(42 / 50)$ cases in control group were primigravida and rest was second gravida (table 1). Mean Bishop score in both the groups were comparable before administration of drug, but changes in mean Bishop score was statistically significant after administration of drug ( $\mathrm{p}$ value $<0.001)$. 
Mean Bishop score after administration of drug in study group was $5.5 \pm 0.54$ and control group was $4.16 \pm 0.76$ (table 2).

\begin{tabular}{|c|c|c|c|}
\hline \multicolumn{2}{|c|}{ Characteristics } & \multirow{2}{*}{$\begin{array}{l}\begin{array}{l}\text { Study group } \\
\text { (n=50) }\end{array} \\
18(36 \%)\end{array}$} & \multirow{2}{*}{$\begin{array}{l}\begin{array}{l}\text { Control group } \\
(\mathbf{n}=\mathbf{5 0})\end{array} \\
16(32 \%) \\
\end{array}$} \\
\hline Age in years & $\leq 20$ & & \\
\hline & $21-25 y r s$ & $21(42 \%)$ & $29(58 \%)$ \\
\hline & $26-30 \mathrm{yrs}$ & $9(18 \%)$ & $5(10 \%)$ \\
\hline & $31-35 y r s$ & $2(4 \%)$ & $0(0 \%)$ \\
\hline \multicolumn{2}{|c|}{ Mean \pm SD (Years) } & $22.2 \pm 2.8$ & $21.9 \pm 2.8$ \\
\hline Gravida & Primi & $39(78 \%)$ & $42(84 \%)$ \\
\hline & $\mathrm{G} 2$ & $11(22 \%)$ & $8(16 \%)$ \\
\hline
\end{tabular}

SD: Standard deviation

Out of 50 patients $33(66 \%)$ patients had vaginal delivery in study group. Seventeen out of fifty (34\%) patients had caesarean section in study group which was less as compared to control group $68 \%(34 / 50)$, but the difference in both the group was not statistically significant. Most common indication for caesarean section in both groups was meconium stained liquor followed by induction failure (table 3).

Table 2: Effect of drug ISMN (Isosorbide mononitrate) on mean Bishop score

\begin{tabular}{lllll}
\hline $\begin{array}{l}\text { Sl. } \\
\text { No }\end{array}$ & $\begin{array}{l}\text { Mean Bishop } \\
\text { score }\end{array}$ & $\begin{array}{l}\text { Study } \\
\text { group }\end{array}$ & $\begin{array}{l}\text { Control } \\
\text { group }\end{array}$ & $\begin{array}{l}\text { P } \\
\text { value }\end{array}$ \\
\hline 1 & Before drug & $3.86 \pm 0.59$ & $3.9 \pm 0.5$ & $0.28(\mathrm{NS})$ \\
2 & After drug & $5.5 \pm 0.84$ & $4.16 \pm 0.76$ & $<0.0001$ \\
\hline NS: Statistically non significant & & \\
\hline
\end{tabular}

Table 3: Delivery outcomes

\begin{tabular}{lllll}
\hline Outcomes & & $\begin{array}{l}\text { Study } \\
(\mathbf{n = 5 0 )}\end{array}$ & $\begin{array}{l}\text { group } \\
(\mathbf{n = 5 0 )}\end{array}$ & $\begin{array}{l}\text { P } \\
\text { value }\end{array}$ \\
\hline Mode of & LSCS & $17(34 \%)$ & $34(68 \%)$ & 0.4626 \\
delivery & Vaginal Delivery & $33(66 \%)$ & $16(32 \%)$ & $(\mathrm{NS})$ \\
\hline Indications of & Meconium stained liquor & $11(64.7 \%)$ & $19(55.88 \%)$ & 0.67 \\
caesarean & Pathological CTG & $2(11.76 \%)$ & $3(8.82 \%)$ & $(\mathrm{NS})$ \\
section & Induction failure & $4(23.5 \%)$ & $12(35.29 \%)$ & \\
\hline \multicolumn{4}{l}{ LSCS - Lower } & segment caesarian section, CTG - Cardiotocography, NS - Non significant \\
\hline
\end{tabular}

Table 4: Obstetrics outcome

\begin{tabular}{lllll}
\hline $\begin{array}{l}\text { Obstetrics } \\
\text { outcomes }\end{array}$ & & $\begin{array}{l}\text { Study group } \\
\text { (n=33) }\end{array}$ & $\begin{array}{l}\text { Control } \\
\text { group (n=16) }\end{array}$ & $\begin{array}{l}\text { P } \\
\text { value }\end{array}$ \\
\hline & 0 & $4(12.12 \%)$ & 0 & \\
Number of misoprostol & 1 & $6(18.18 \%)$ & 0 & \\
doses required for vaginal & 2 & $20(60.6 \%)$ & $1(6.25 \%)$ & $0.2534(\mathrm{NS})$ \\
delivery & 3 & $3(9 \%)$ & $13(81.25 \%)$ & \\
& 4 & 0 & $2(12.5 \%)$ & \\
\hline Need of oxytocin to achieve & Yes & $3(9.1 \%)$ & $13(81.25 \%)$ & 0.001 (statistical \\
vaginal delivery & No & $30(90.9 \%)$ & $3(18.75 \%)$ & significant) \\
\hline Time interval between & $<12 \mathrm{hrs}$ & $18(54.54 \%)$ & 0 & 0.0002 (statistica \\
induction to vaginal delivery & $\geq 12 \mathrm{hrs}$ & $15(45.46 \%)$ & $16(100 \%)$ & -lly significant) \\
\hline NS: Statistically non significant & & & \\
\hline
\end{tabular}

Out of vaginal delivery most of patients $60.6 \%(20 / 33)$ delivered with two doses of misoprostol as compared to control group where $76.48 \%$ (13/16) required 3 doses to achieve active labour and vaginal delivery. Oxytocin was not required in majority of cases $(90.9 \%)$ in study group whereas $81.25 \%$ cases in control group required oxytocin to achieve vaginal delivery. The induction to delivery interval was between 6-12 hrs in $17(51.5 \%)$ in study group while in control group, no case could deliver in this interval. Most of cases $93.75 \%$ in control group had induction to delivery interval between $12-18 \mathrm{hrs}$ as compared to $15(45.4 \%)$ cases in control group which was statistically significant (table 4).

Table 5: Maternal and neonatal outcomes

\begin{tabular}{lllll}
\hline Categories & & $\begin{array}{l}\text { Study } \\
\text { group } \\
\text { (n=50) }\end{array}$ & $\begin{array}{l}\text { Control } \\
\text { group } \\
\text { (n=50) }\end{array}$ & $\begin{array}{l}\text { P } \\
\text { value }\end{array}$ \\
\hline Adverse & Headache & $26(52 \%)$ & 0 & \\
effects of & Palpitation & 0 & 0 & \\
mother & Hypotension & 0 & 0 & \\
\hline Birth & $2-2.5$ & $7(14 \%)$ & $15(30 \%)$ & \\
weight & $2.51-3$ & $30(60 \%)$ & $28(56 \%)$ & $0.11(\mathrm{NS})$ \\
(Kg) & $3.01-3.5$ & $12(24 \%)$ & $7(14 \%)$ & \\
& $3.51-4$ & $1(2 \%)$ & 0 & \\
\hline Apgar & $<7$ & 0 & $3(6 \%)$ & \\
score & 7 to 8 & $2(4 \%)$ & $3(6 \%)$ & $0.2(\mathrm{NS})$ \\
(5 minutes) & 9 & $48(96 \%)$ & $44(88 \%)$ & \\
\hline NICU & 0 & $33(66 \%)$ & $16(32 \%)$ & \\
admission & 1 & $13(26 \%)$ & $7(14 \%)$ & $0.2(\mathrm{NS})$ \\
(Days) & 2 & $4(8 \%)$ & $23(46 \%)$ & \\
\hline \multicolumn{5}{l}{ NS - Non significant, NICU - Neonatal intensive care unit } \\
\hline
\end{tabular}

Most common maternal adverse effect was headache observed in $26(52 \%)$ cases in study group. No adverse effect was observed in control group. Majority of babies had birth weight between 2.51-3 $\mathrm{kg}$ in both groups and were comparable. Forty eight (96\%) babies in study group and 44 (88\%) babies in control group had Apgar score of 9. NICU care was not required in $33(66 \%)$ babies in study group and $16(32 \%)$ babies in control group. The findings were not statistically significant (table 5).

\section{Discussion}

Prostaglandins like PGE1 and E2 are most widely accepted methods for cervical ripening but the major problems associated with their use is the induction of uterine contraction leading to uterine hyperstimulation, meconium stained liquor and FHR abnormality due to stimulatory effect on the myometrium. ${ }^{10}$ The discovery of the presence of NO generating system in the cervix and their pivotal role in the ripening of cervix may prove to be a major turning point for cervical ripening prior to labour induction. The major advantage of using NO donors as a cervical ripening agent lies in the fact that they induce cervical ripening without stimulating myometrial contractility.

Recently the efficacy and safety of NO donors ISMN for outpatient pre-induction cervical ripening has been 
investigated and results of these studies indicated that this agent shows some promise as an effective cervical ripening agents. $^{11,12}$

In our study, we compared ISMN with placebo for cervical ripening prior to induction of labour with misoprostol in each group. The two groups were comparable in demographic parameters such as age and parity. We found statistically significant change in mean Bishop's score after $16 \mathrm{hrs}$ in ISMN group as compared to placebo. These results are consistent with study conducted by other authors ${ }^{13-16}$. Solimun ${ }^{17}$ noted statistically significant improvement in mean Bishop score in combination therapy of ISMN with misoprostol as compared to ISMN or misoprostol alone. Their result have substantiated that combined use of these drugs may be synergistic and more effective in cervical ripening. However Bullarbo et al ${ }^{18}$ failed to demonstrate any significant change in mean Bishop score after ISMN administration as compared to placebo, though number of women going into labour after $24 \mathrm{hrs}$ of drug administration was significantly more in ISMN group ( $\mathrm{p}$ value 0.01 ). This discrepancy in the finding could be due to higher baseline Bishop score in ISMN group before drug administration as compared to placebo group.

In current study, the number of vaginal deliveries was more than twice in the study group as compared to control group, thus reducing the caesarean section to half in study group. But the results were not statistically significant. However no statistical significant difference noted in rates of vaginal deliveries and caesarean section rate between ISMN or misoprostol group in study conducted by other authors ${ }^{13,19}$. All these trial have used ISMN alone or in combination with misoprostol but not sequentially as we did in our study. The most common indication for caesarean section in both groups in our study was meconium stained liquor which may be due to the use of misoprostol in both groups. Similarly Collingham et al ${ }^{20}$ reveal that ISMN is not associated with meconium staining of liquor.

In the present study, induction failure was more common in control group as compared to study group. Chanrachakul et $\mathrm{al}^{19}$ noticed less induction failure in misoprostol alone group as compared to ISMN alone group and results were statistically significant. Induction failure was not statistically different in misoprostol plus ISMN group (27.2\%) as compared to misoprostol plus placebo group (23.5\%) in trial conducted by Abdellah et al ${ }^{13}$. This contrast in finding may be due to smaller sample size in our study (100 as compared to 290) and also sequential use of misoprostol after $16 \mathrm{hrs}$ of either ISMN or placebo as compared to concurrent use of the drugs in their trial.

In our study, number of misoprostol doses required to achieve vaginal delivery was less in study group as compared to control group whereas, oxytocin was required in $81.25 \%$ cases in the control group as compared to only $9.09 \%$ cases in the study group. While Soliman ${ }^{17}$ observed that the mean durations of the first and the second stage of labor were significantly shorter in the misoprostol and the combination therapy groups compared with the IMN group (p - 0.048 and 0.02 , respectively). Oxytocin was needed in 61 women $(93.8 \%)$ in the IMN group compared with 14 women $(21.5 \%)$ in the misoprostol and 17 women $(25.8 \%)$ in the combination therapy groups $(\mathrm{p}<0.0001)$. However Soliman $^{17}$ compared the ISMN, with misoprostol and combination of two drugs in contrast to our study where we use sequential use of ISMN and misoprostol and misoprostol group.

In the present study, induction to delivery interval was shorter for most of the cases (54.5\%) in the study group, who delivered vaginally within $12 \mathrm{hrs}$ while all cases in control group delivered vaginally beyond $12 \mathrm{hrs}$. Similar results were found in trial conducted by Hamideh et $\mathrm{al}^{16}$. However Chanrachakul et al ${ }^{19}$ noticed significantly longer induction to delivery interval in ISMN alone group as compared to misoprostol alone group. This discrepancy in the findings may be due to comparing ISMN alone with misoprostol alone in their trial in contrast to our study where ISMN with misoprostol was compared with misoprostol alone. This shows that combination of misoprostol with ISMN has synergistic effect on cervical ripening as compared to ISMN alone.

In our study mild headache was noted in ISMN group, which responded to simple analgesic while other adverse effects like palpitation, dizziness and hypotension were not reported by patients in either group. These results were similar to the findings in other trials. ${ }^{15,20}$ Both the groups were comparable in neonatal birth weight in our study. In present study, 5 minute neonatal APGAR scores were comparable in both the groups. In our study, there was no statistical difference in neonatal NICU admissions in the two groups ( $\mathrm{p}$-value - 0.2). These findings are consistent with other trials. ${ }^{13,19,20}$ 
The New Indian Journal of OBGYN. 2021 (January-June);8(2)

\section{Conclusions}

Nitric oxide (NO) donor, Isosorbide mononitrate is safe, well tolerated and effective cervical ripening agent, which induces ripening of cervix without causing uterine contraction. In present study, use of NO donors prior to labour induction has lead to significant improvement in mean bishop score and also reduced the number of misoprostol doses required to achieve vaginal delivery in study group. However, larger studies may be required.

\section{Conflict of interest: None. Disclaimer: Nil.}

\section{References}

1. Moore LE, Rayburn WF. Elective induction of labour. Clin Obstet Gynecol. 2006 Sep; 49(3): 698-704.

2. Luthy DA, Malmgren JA, Zingheim RW. Cesarean delivery after elective induction in nulliparous women: the physician effects. Am J Obstet Gynecol. 2004 Nov; 191(5): 1511-5.

3. Vrouenraets FP, Roumen FJ, Dehing CJ, Van Den Akker ES, Aarts MJ, Scheve EJ. Bishop score and risk of cesarean delivery after induction of labor in nulliparous women. Obstet Gynecol. 2005 Apr; 105(4): 690-7.

4. Tenore JL. Methods for cervical ripening and induction of labor. Am Fam Physician. 2003 May 15; 67(10): 2123-8.

5. Kelsey HA, Muirhead JM, Theobald GW. The pitocin drip. J Obstet Gynecol Br Emp. 1956 Oct; 63(5): 641-62.

6. Keirse MJ. Prostaglandins in preinduction cervical ripening. Meta-analysis of worldwide clinical experience. J Reprod Med. 1993 Jan; 38(1Suppl): 89-100.

7. Wing DA. Labour induction with misoprostol. Am J Obstet Gynecol. 1999; 181:339-45.

8. Hofmeyr GJ, Gulmezoglu AM. Vaginal misoprostol for cervical ripening and labour induction in late pregnancy. Cochrane Database Syst Rev. 2001; 1: CD000941.

9. Ledingham MA, Thomson AJ, Greer IA, Norman JE. Nitric oxide in parturition. BJOG. 2000; 107: 581-93.

10. Chwalisz K, Garfield RE. Nitric oxide as the final mediator of cervical ripening. Human Reproduction. 1998; 13: 245-52.
11. Chwalisz K, Shao-Qing S, Garfield RE, Beier HM. Cervical ripening in guinea-pigs after a local application of nitric oxide. Hum Reprod. 1997 Oct; 12(10): 2093-101.

12. Bates $\mathrm{CD}$, Nicoll AE, Mullen AB, Mackenzie F, Thomson AJ, Norman JE. Serum profile of isosorbide mononitrate after vaginal administration in the third trimester. British Journal of Obstetric and Gynaecology. 2003 Jan; 110(1): 64-7.

13. Abdellah MS, Hussien M, Aboalhassan A. Intravaginal administration of isosorbide mononitrate and misoprostol for cervical ripening and induction of labor: a randomized controlled trial. Arch Gynecol Obstet. $2011 \mathrm{Jul} ; 284(1):$ 25-30.

14. Bollapragada SS, MacKenzie F, Norrie JD, Eddama O, Petrou S, Reid M, et al. Randomized placebo- controlled trial of outpatient (at home) cervical ripening with isosorbide mononitrate (IMN) prior to induction of labour - clinical trial with analyses of efficacy and acceptability. BJOG. 2009 Aug; 116(9):1185-95.

15. Vidanagamage RS, Goonewardene IM. The efficacy of two different doses of vaginal isosorbide mononitrate in pre induction cervical ripening: a double blind randomized controlled trial. Ceylon Medical Journal. 2011 Sep; 56(3): 91-100.

16. Hamideh Y, Abedi P, Najar S, Angali KA. The impact of isosorbide mononitrate on cervical ripening and labor induction in primiparous women with term pregnancy: A double- blind, randomized, controlled trial. Iran J Nurs Midwifery Res. 2013 May-Jun; 18(3): 246-50.

17. Soliman AT. A comparision of isosorbide mononitrate, misoprostol and combination therapy for preinduction cervical ripening at term: a randomized controlled trial. Tanta Medical Sciences Journal. 2013; 41(4): 310-7.

18. Bullarbo M, Orrskog ME, Andersch B, Granstrom L, Norstrom A, Ekerhovd E. Outpatient vaginal administration of the nitric oxide donor isosorbide mononitrate for cervical ripening and labour induction postterm: A randomized controlled study. Am J Obstet Gynecol. 2007 Jan; 196(1):50.e1-5.

19. Chanrachakul B, Herabutya Y, Punyavachira P. Randomized trial of isosobide mononitrate versus misoprostol for cervical ripening at term. Int J Gynaecol Obstet. 2002 Aug; 78(2):139-45.

20. Collingham JP, Fuh KC, Caughey AB, Pullen KM, Lyell DJ, El-Sayed YY. Oral Misoprostol and Vaginal Isosorbide Mononitrate for Labour Induction: A 
The New Indian Journal of OBGYN. 2021 (January-June);8(2)

Randomized Controlled trial. Obstet Gynecol. 2010; 116:121-6.

Shikha Agarwal ${ }^{1}$, Kusum Dogra ${ }^{2}$
${ }^{1}$ Assistant Professor, Department of Obs \& Gynae, SGRRIMHS \& SMIH, Dehradun, India; ${ }^{2}$ Assistant Professor, Department of Obs \& Gynae, UCMS \& GTB hospital, Delhi, India. 